OPEN ACCESS

Citation: J. Bright, D. Garzia, J. Lacey, A. H. Trechsel (2020) The representative deficit in different European Party Systems: an analysis of the elections to the European Parliament 20092014. Quaderni dell'Osservatorio elettorale - Italian Journal of Electoral Studies 83(1): 45-57. doi: 10.36253/ qoe-9531

Received: December 17, 2019

Accepted: February 27, 2020

Published: July 28, 2020

Copyright: (C) 2020 J. Bright, D. Garzia, J. Lacey, A. H. Trechsel. This is an open access, peer-reviewed article published by Firenze University Press (http://www.fupress.com/qoe) and distributed under the terms of the Creative Commons Attribution License, which permits unrestricted use, distribution, and reproduction in any medium, provided the original author and source are credited.

Data Availability Statement: All relevant data are within the paper and its Supporting Information files.

Competing Interests: The Author(s) declare(s) no conflict of interest.

\section{The representative deficit in different European Party Systems: an analysis of the elections to the European Parliament 2009-2014}

\author{
Jonathan Bright ${ }^{1}$, Diego Garzia ${ }^{2, *}$, Joseph Lacey ${ }^{3}$, Alexander H. \\ TRECHSEL ${ }^{4}$ \\ ${ }^{1}$ University of Oxford, UK \\ ${ }^{2}$ University of Lausanne, Switzerland \\ ${ }^{3}$ University College Dublin, Ireland \\ ${ }^{4}$ University of Lucerne, Switzerland \\ *Corresponding author. E-mail: diego.garzia@unil.ch
}

\begin{abstract}
This paper explores the extent to which different party systems in Europe effectively represent their citizens. We argue that many European countries suffer from a "representative deficit", which occurs when a significant portion of citizens have to vote for a political party whose stated views are actually quite different from their own. We measure the extent of this deficit in different European countries using data from EU Profiler and euandi, two Voting Advice Applications which served millions of users during the EP elections in 2009 and 2014 respectively. We find wide variation in the extent to which political parties are accurately tuned in to the preferences of their voters, a variation which is not clearly linked to the number of political parties or the proportionality of the electoral system. We attempt to explain some of this variation, and explore the reasons why some party systems offer better representation than others.
\end{abstract}

Keywords. Elections, voting advice applications, representation.

\section{INTRODUCTION}

If it is the case that ideational congruence between representatives and the represented is the "central normative problem of democracy" (Rehfeld, 2009: 214; see also: Bolleyer and Reh, 2012), then the central questions for empirical research on the quality of democracy pertain to (a) measuring ideational symmetry between representatives and the represented and (b) explaining the factors that lead to variation in this symmetry. This paper attempts to contribute towards this enterprise by carrying out both tasks in relation to EU member states. In particular, our aim is to measure the "representative deficit" (i.e. the degree to which the average citizen fails to find complete ideational representation) in each member state as well as to identify the factors that might explain the (sometimes large) differences in representative quality between member states. 
There is a considerable body of literature on ideational symmetry and representation. However, most of these works have focused on aggregate-level congruence between party elites and voters on a left-right scale (e.g. Dalton et al., 2011; Rohrschneider and Whitefield, 2012; Thomassen and Schmitt, 1999). This is a weakness: as Dalton (2015: 1) claims, "the structure of political competition is becoming more complex, new issues are entering the political agenda, and new parties are engaging the voters". Against this background, this paper hence aims to improve on existing efforts by going beyond a unidimensional left-right scale towards a multidimensional approach. This is made possible by reliance on two unique datasets made available by the 2009 EU Profiler and its follow-up instalment euandi in 2014, both Voting Advice Applications [hereafter: VAAs] designed for use in each member state in the lead up to elections for the European Parliament (see: Trechsel and Mair, 2011; Garzia et al., 2017). Unlike other data-sets which deal with citizens attitudes across Europe, available from Eurobaromater or the European Election Study for example, these VAAs were designed with the specific goal of ideationally matching citizens with parties on the basis of a large number of policy issues including economic as well as socio-cultural aspects of the political competition, and have hence yielded a rich data-set for measuring the congruence between participating users and profiled parties which goes well beyond the traditional left-right separation. In this way, they offer a unique opportunity to systematically compare deficits in different European countries across countries and time.

We distinguish between two broad sets of variables that may affect the quality of representation in a political system, that is, those pertaining to the organisation of the regime and those relating to the political community or civil society. Building on theory that emphasises the importance of the quality of the communicative relationship between the regime and citizens (both as individuals and collectivised in organisations), we focus on those variables relating to the regime that may affect the government's degree of responsiveness to citizens, as well as those variables relating to civil society that are likely to affect citizens' ability and willingness to communicate with their representatives.

The next section explains in more detail the representative deficit, as well as our understanding of the relationship between communication and representation. On this basis, we attempt to identify those variables relating to the communicative quality of a regime and civil society that are expected to affect the quality of representation in a democratic system. Following this, we outline our data and methods. In the ensuing results section, we find descriptive evidence to confirm that the quality of representation is indeed in decline across Europe, while the representative deficit in Central and Eastern Europe taken as a whole is significantly worse than in Western Europe. Concerning our explanatory variables, we find that many of the usual suspects relating to the regime do not in fact explain differences in the quality of representation between countries (i.e., number of parties, electoral size of country, level of decentralisation, proportionality of its electoral system, etc.). When it comes to those factors regarding civil society (i.e., press freedom, voice and accountability, electoral participation) we find significant explanatory power. The final section concludes with a discussion of the results and their potential implications.

\section{THEORETICAL FRAMEWORK}

\section{The Representative Deficit}

The sum of policy options and preferences in a polity which can be used to make representative promises can be conceptualised in terms of a multidimensional "political space" (see, e.g., Benoit and Laver, 2012). In such a political space, each dimension is a single policy issue (for example, the extent to which the unemployed should be given benefits), with the range of preferences on the issue being equivalent to the total range of the dimension (in this example, from no benefits at all to very generous benefits). Theoretically, every citizen in a polity can be located at some point within this political space, and so can the political parties which compete to represent them.

As Chantal Mouffe (1999) argues, the whole of society can never be represented since the very nature of identity formation and choice necessitates exclusionary tendencies. What this means in this context is that the choice for one policy position is always a choice against a whole set of others. Citizens have a wide variety of preferences: it is likely that, even in a moderately sized polity, political space is effectively full, with every point occupied by at least one person. There are, by contrast, typically only a few political parties which contest elections. This makes it inevitable that the great majority of citizens cannot find a party whose position in political space coincides exactly with their own. There will always be, in other words, a mismatch in the extent to which the opinions of citizens are represented in their polity, something which has previously been described as a "representative deficit" (Alvarez et al., 2014: 239). However, public opinion is not distributed evenly throughout political space, and nor are political parties. Hence the extent to which representation is in deficit will vary, 
relative to the positioning of both parties and the public at large.

Much of the literature on representation is structured around the study of political parties (Dalton et al., 2011; Rohrschneider and Whitefield, 2012; Thomassen and Schmitt, 1999). However from the perspective of parties the problem of representative deficit is theoretically complex, because it is a result of the behaviour of the party system as a whole, not individuals within it. For example, if we assume, following Downs (1957), that parties are essentially "vote maximizers", the need to pursue public opinion would push the majority of parties to move towards the centre ground, which would leave public opinion on the extremes less and less catered for and result in a homogenization of the political offer. Hence a party level incentive to improve representation would result in an increasing representative deficit. Furthermore, vote-seeking models of party behaviour have been heavily criticised, with examples abounding of parties abandoning the centre ground. For this reason, our major interest in this paper lies in considering factors relating to the system of democracy as a whole which might explain not just the behaviour of individual parties but their distribution throughout political space.

\section{Representation and Communication: Some Hypotheses}

Our particular focus is on the communicative relationship between citizens within a polity and political actors. In many ways deliberative democrats have been successful in achieving what Simone Chambers (2012) refers to as the aim of moving political science from a vote-based to a talk-based agenda. Certainly, regardless of whether or not one subscribes to one or other theory of deliberative democracy, the crucial role of discursive engagement between representatives and the represented in promoting good democratic representation cannot be ignored. To put it in James Bohman's words (2010), the goal of democracy is to turn citizens' communicative freedom into communicative power. That is to say, to the extent that citizens are endowed with the basic needs and liberties required to organise and participate politically (communicative freedom), they should be ideally able to translate the many discourses that go on in their associations into a wider discussion with their representatives who, in carrying out their law-making functions, are responsive to the discursive force behind these exchanges (communicative power). This account need not be at odds with the fact that democracy is essentially a competitive system that, while requiring compromise, is not necessarily geared towards deliberative consensus.
The key question then is under what conditions is citizens' communicative freedom likely to be translated into communicative power? Understanding the problematic thusly, we must analyse those factors which are likely to most affect (a) the responsiveness of representatives to the discourse of citizens and their organisations and (b) the extent to which citizens are willing and able to express their communicative freedom.

Surveying standard accounts of democracy, it is possible to highlight a range of variables that are expected to have an impact on either of the above dependent variables. Concerning those factors expected to affect the responsiveness of representatives, we highlight (i) the electoral system, (ii) the number of parties, (iii) the size of the country, (iv) the level of decentralisation, and (v) the length of time a country has been democratic. Briefly, we can explain the rationale behind the choice of these independent variables.

For the first independent variable, we expect that Proportional Representation, rather than First-Past-ThePost electoral systems, will give rise to better representation (for an elaboration see: Gerring and Thacker, 2008: 13-14; 48-57). The winner takes all nature of the latter can be seen as incentivising party drift towards the median voter, whereas the more even distribution of parliamentary seats for which the former system is designed provides an incentive for at least some parties to rely on voters from their ideological support base. This helps to ensure that the values and interests of nonmedian voters do not get left behind in public discourse. Closely related to this variable is the number of parties in a political system. Quite simply, when there is a greater partisan offer, one can expect that citizens will have more opportunities to find a better electoral fit and thereby reduce their representative deficit (Bright et al., 2016).

The size of the country and the level of decentralisation are variables that are closely related to one another. From Montesquieu (1989 [1750]) to Robert Dahl (1989), the size of the polity has been taken to have a major impact on the quality of representation. The more voices there are per representative, the less likely it is that these representatives will be successful in being able to reconcile the diverging values and interests of those she represents. One can therefore expect that smaller countries and countries that are highly decentralised, so that decisions are taken as close as possible to citizens on the local or sub-federal level such that only the remainder is left to national representatives, will have a better quality of representation.

Democracy is more than just free and fair elections, but a political culture and set of norms support- 
ing strong communicative relationships between representatives and the represented. However, a democratic political culture does not emerge overnight and is often haunted by some of the non-democratic habits characterising the previous regime. Therefore we may expect that the longer a democratic regime is in place the more likely it is that the political culture will have taken on the appropriate habits for establishing a good standard of representation.

When it comes to citizens' willingness and ability to express their communicative freedom, we identify several independent variables that are expected to be significant: (vi) freedom of the press; (vii) voice and accountability; and (viii) political participation. The quality of these democratic features is not easy to measure and often have multiple components. In recent years, however, data sets have emerged with relatively reliable measures and we draw on these.

Regarding the first of these variables, freedom of the press is widely recognised to be an essential condition for democracy. The press is the primary forum in which competitive politics is mediated. It serves as a crucial discursive conveyer belt between representatives and the represented (Habermas, 1996). Significant restrictions on media freedom would interfere with this mechanism, excluding a wide range of views at the expense of a more circumscribed set, ultimately undermining the communicative relationship between citizens and representatives. In order to measure the variable of press freedom, we draw on data from the World Press Freedom Index, a data set based on an assessment of press freedom within countries across the world from a range of actors, including journalists, academics and activists (Becker et al., 2007).

Voice and Accountability is a category of indicators within the wider World Bank Governance Indicators project - a data-set measuring the extent to which citizens can effectively express their views and to which public officials can be publically held to account (Kaufmann et al., 2009). This dataset is also compiled from assessments by civil society actors and the like. Effectively, the less citizens can be seen as capable of raising their voice and the less reason politicians have to fear accountability mechanisms, the less likely it is that there will be communicative conditions that are favourable to the quality of representation. A further indicator we take in this regard is the level of turnout in elections. Higher turnout can be expected to impact positively on the representative deficit since the more citizens who are engaged in the electoral process across the society, the more likely it is that representatives will be incentivised to take a wide range of preferences into account.
A final (control) variable we consider, which does not fall within the categories of regime or public sphere is the level of economic performance, imperfectly measured by GDP. One might expect greater wealth to give a political system the resources for developing robust democratic institutions, in addition to giving citizens the required leisure for the kind of political engagement required for democratic accountability. One might also expect that the more resources at a government's disposal the greater would be the chances of it meeting the preferences of more citizens. Indeed, the fiscal ability of the government to meet the demands of conflicting identities, even in ethnically divided societies like Belgium, has been given as an important reason for political stability (Hooghe, 2003).

\section{DATA AND METHODOLOGY: USING VAA DATA TO MEASURE PARTY-VOTER PROXIMITY IN THE POLITICAL SPACE}

In this paper, we measure the political space, and hence its inherent representative deficit, in 27 different EU member states ${ }^{1}$, using data drawn from the $E U$ Profiler and euandi. Although different in some respects, VAAs share a common underlying principle: they help users in their act of making a party choice and casting a vote by comparing their policy preferences on major issues with the programmatic stances of political parties on the same issues (for a review, see: Garzia and Marschall, 2016; 2019). The core of every VAA that enables this comparison is a list of political issue statements formulated by the body that created the VAA, e.g., "social programs should be maintained even at the cost of higher taxes". ${ }^{2}$ Each user can express her degree of agreement or disagreement with each particular statement (see Figure 1 , left). The resulting issue preferences of the user are then matched with the positions of the parties included in the VAA on these same issues (only parties already represented in parliament or with a reasonable chance to achieve representation in the election under analysis have been included in the VAA system). After comparing the user's profile with that of each party, the applica-

\footnotetext{
${ }^{1}$ For reason of longitudinal comparability, we decided to exclude Croatia from the sample insofar as this country only took part in EP elections in 2014

${ }^{2}$ For the selection of the 28 statements included in both VAAs, party manifestos were analysed to understand not only how frequently certain policy areas were mentioned, but also the 'urgency' with which parties discussed individual issues. At the same time, opinion polls, earlier party manifesto coding, groups of experts, academics and journalists were consulted for what they considered to be the key issues in the election. The various lists were then analysed together and the issues that occurred most frequently and urgently were selected for inclusion.
} 


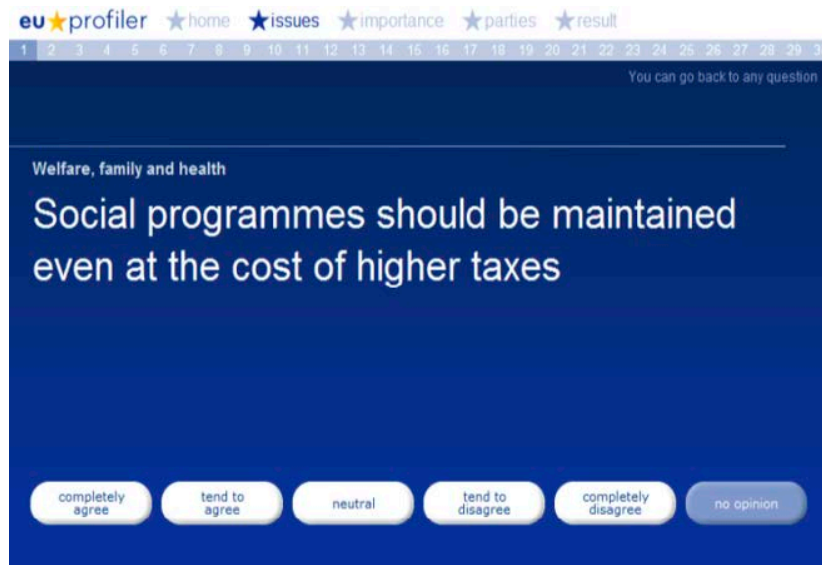

\begin{tabular}{|c|c|c|}
\hline & Party & Match \\
\hline 1 ता & LDP & $76.0 \%$ \\
\hline $2 \mathrm{CDA}$ & CDA & $73.2 \%$ \\
\hline 3 Prot & PvdA & $71.4 \%$ \\
\hline 42 & GL & $69.6 \%$ \\
\hline 5 D66 & D66 & $67.9 \%$ \\
\hline 6 SP. & SP & $67.0 \%$ \\
\hline $7=$ & $\mathrm{CU} / \mathrm{SGP}$ & $67.0 \%$ \\
\hline $8 \sqrt{1}$ & New & $66.3 \%$ \\
\hline $9 B$ & VVD & $62.5 \%$ \\
\hline 10 媐 & PudD & $62.5 \%$ \\
\hline
\end{tabular}

Fig. 1. Example of a VAA statement (L); the 'voting advice' provided in the results screen (R). Source: www.euprofiler.eu.

tion produces a "voting advice", usually in the form of a rank-ordered list, at the top of which stands the party closest to the user's policy preferences (see Figure 1, right) $)^{3}$.

The concept of "representative deficit" was first derived and empirically measured by Alvarez et al. (2014: 239). In analogy to the work of these authors, we calculate the representative deficit by looking at the extent to which each individual matches up to all other political parties in the national space, following a matching rule developed by the EU Profiler itself. Each issue statement produces responses on a 5-point Likert scale, from strongly disagree to strongly agree. The distance from party to individual is measured using this scale. The representative deficit variable ranges thus from 0 to 100 percent and corresponds to the distance between a potential perfect overlap of 100 percent and the real extent of overlap between the best-matching party "on offer" and the user's preferences, as shown to the user in the match-list visualization of the VAA. The smaller the representative deficit, therefore, the better the policy congruence between the best-matching party in a given voting space and a VAA user's preferences.

The information produced by the VAA is useful to us in two major respects. First, with its numerous issue statements, it provides us with a measure of where parties are located in a high-dimensional issue space. The methodology employed in both EU Profiler and euandi involved an iterative approach that integrates party selfplacement and expert assessment into the final positioning of political parties on the thirty political statements included in the VAAs (for a deeper discussion, see: Gar-

\footnotetext{
${ }^{3}$ The matching algorithm of both VAAs is based on the city bloc method. For a better description of the calculation of user-party overlaps, see: www.euprofiler.eu and www.euandi.eu
}

zia et al., 2015). The information produced by these VAA projects is also useful insofar as it allows a straightforward comparison between the parties' location in the policy space and that of a large array of users/voters. Traditional analyses of the ideological positions of the general population commonly resort to traditional surveys. Nonetheless, VAAs would seem to feature a number of advantages vis-a-vis more traditional research tools. For one thing, VAAs are able to measure users' position over a much larger set of policy issues as compared to more "traditional" representative samples such as national election studies. Even more importantly, they allow comparisons of the issue positions of parties and voters using the same data source. In turn, this can help assessing our research questions by means of a straightforward measurement of the extent to which parties and voters are mutually congruent. ${ }^{4}$

By way of illustration, Figures 2 and 3 below visualize the state of political space in the United Kingdom and France respectively. These figures simplify the various questions asked into two axes, namely, a left/right dimension and a pro/anti EU dimension. The density plot shows the location of individuals in our sample, with smaller concentric circles indicating concentrations of people.

${ }^{4}$ Note, however, that one of the major problems linked to VAA research in this field is, for evident reasons, the highly non-representativeness of VAA usage. The problem of self-selection into the sample, which results in its non-representativeness, can be possibly mitigated in the light of Almond's seminal distinction between the general public, the attentive public (which largely informs the general public by osmosis) and the elite public (e.g., politicians, high level civil servants). In a sense, VAA samples primarily come from the attentive public of each European country (see: Marschall, 2014). Under the assumption that it is the attentive public that informs the general public, then VAA samples may be thought to serve as the next best gauge of public opinion than a random sample of the general public itself. 


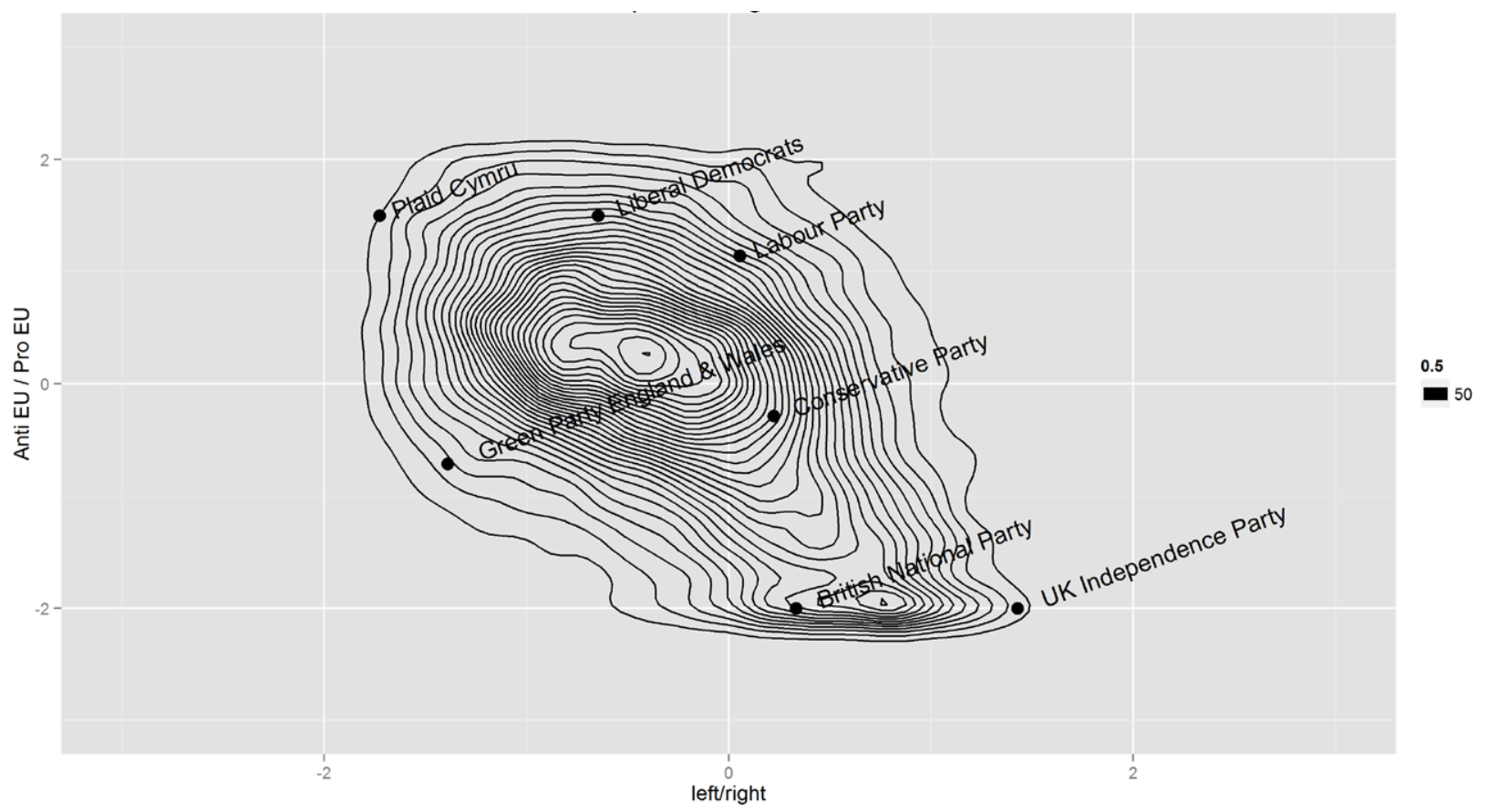

Fig. 2. The Political Space in the UK.

The plot for the UK shows two poles, one slightly to the left of centre and slightly more pro-European, and one slightly to the right of centre and strongly anti-European. The distribution of parties around these poles is intriguing: while all lie within the outermost line of the density plot, only the British National Party really emerges as close to one of the two poles. The plot for France shows only one pole, by contrast, further to the left and more pro-European than the UK. Again, interestingly, few parties are anywhere near the centre of this pole, with many lying outside the political space implied by citizens altogether. These plots highlight clearly therefore that the overlap between citizens preferences and political parties is far from perfect, and that the distribution of citizens and parties in political space is complex.

\section{THE REPRESENTATIVE DEFICIT ACROSS DIFFERENT PARTY SYSTEMS: EMPIRICAL FINDINGS}

The mean value of the national representative deficit for the whole sample of EU Profiler users in 2009 is 28.2 per cent $(\mathrm{N}=473,045)$ - that is, on average, users' best matching party in their national constituency leaves about a quarter of their political preferences unrepresented. The figure for euandi users in 2014 is slightly higher $(\mathrm{M}=32.4 ; \mathrm{N}=399,882)$. In Table 1 we present the average value of EU Profiler and euandi users' representative deficit broken down by their country of residence. ${ }^{5}$

Table 1 shows some interesting descriptive findings which are worth commenting on briefly. There are general signs of a worsening of deficits between the 2009 and 2014 rounds, which supports the general thesis that democratic representation is getting worse in Europe. There is also a clear, systematic difference between Western and Eastern Europe, with Eastern European countries having comparatively higher deficits.

These findings complement those of Beate Sissenich (2010: 12), who believes that the nascent and fragile accountability mechanisms in Eastern European countries were set back by the EU's insistence that acceding member states from Eastern Europe transpose community law into national law by streamlining the domestic legislative process (Rose-Ackerman, 2007).

The difference between East and Western Europe exists in both 2009 and 2014, though is narrower in 2014. This narrowing can largely be explained by disproportionately large increases in deficit for Cyprus, Denmark, Finland, Greece, Malta and Portugal. While we do not have a systematic explanation which links all of these countries, it is interesting to note the presence

\footnotetext{
${ }^{5}$ Note that these figures are calculated based on the resulting proximity score between users and the best matching party based on the 17 common statements included in both EU Profiler and euandi.
} 


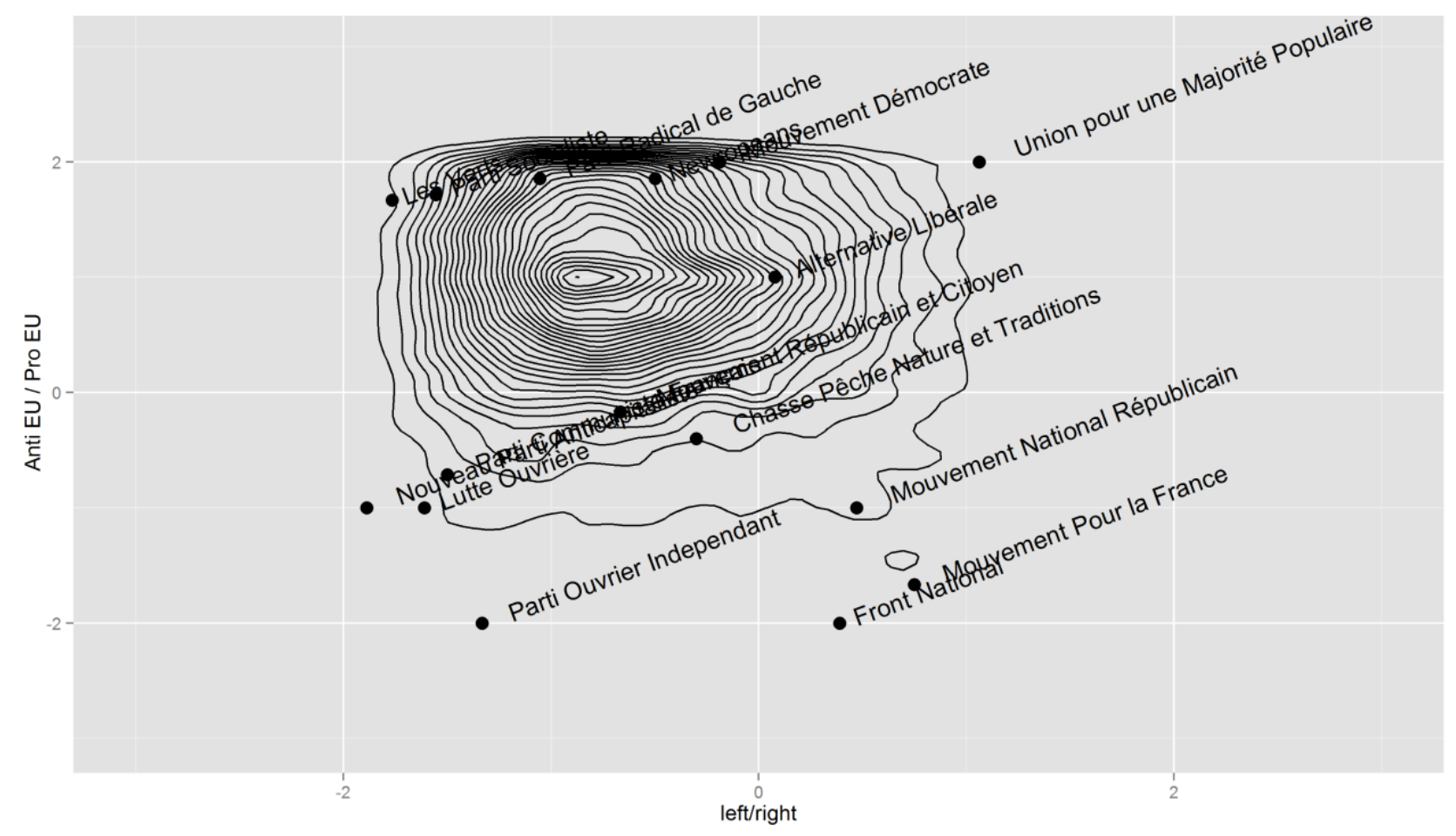

Fig. 3. The Political Space in France.

of Cyprus, Greece and Portugal in this list, as they are three of the countries who were hardest hit by the European debt crisis, and who had to give up some of their fiscal sovereignty. Ireland and Spain, the other countries in this category, also experienced increases in representative deficit above the Western European average increase. This offers some support for the idea that loss of sovereignty in this way has served to worsen the quality of democratic representation in these countries - a thesis widely put forward over the last years in various sectors of the news media but not systematically argued for or empirically tested in academic research.

We will now move on to a series of analytical models which seek to explain variation in representative deficit at the country level. On the basis of our theoretical review, we explore a number of variables which are potentially relevant. In the first block we include all variables related to the political and institutional features of the countries under analysis. Firstly, we code the proportionality of the voting system used in terms of the electoral threshold to gain representation in the European Parliament for a party in a given country. ${ }^{6}$ We expect more competi-

\footnotetext{
${ }^{6}$ Although all EU countries employ a proportional system of seat allocation in EP elections, it is worth highlighting that the ratio between the number of available seats per country and the nominal threshold can vary substantially (e.g., between 1 percent in the case of Germany
}

tive systems (that is, systems with a lower effective electoral threshold) to lead to lower degrees of representative deficit. We also look at the number of political parties, as measured by the number of relevant parties included in the EU Profiler and euandi VAAs (i.e., parties already represented in national and/or EP parliaments as well as parties bearing a reasonable chance to gain representation through that election) as an obvious factor which ought to reduce the extent to which representation is in deficit. We also control for the degree of institutionalization of the party system (measured as the years since a given country became democratic), the extent of decentralization (measured with a dummy coding ' 1 ' all countries in which federal/regional decentralization governance practices are in place) and the electoral size of the country (measured through the number of seats available to that nation in the European Parliament).

The second block of variables includes those related to the public sphere. To this purpose, we resort to summary measures developed by Reporters Without Borders (World Press Freedom Index) and the World Bank (World Governance Indicators: Voice \& Accountability).

to 17 percent in the cases of Cyprus, Malta and Luxembourg). For this reason, we make use of the effective electoral threshold as a way to measure the proportionality of each nation's electoral system. 
Tab. 1. Average Representative Deficit by Country.

\begin{tabular}{|c|c|c|c|}
\hline & 2009 & 2014 & $\Delta 2014-2009$ \\
\hline \multicolumn{4}{|c|}{ Western Europe } \\
\hline Austria & 27,01 & 25,84 & $-1,17$ \\
\hline Belgium & 21,14 & 23,68 & $+2,54$ \\
\hline Cyprus & 26,94 & 43,91 & $+16,97$ \\
\hline Denmark & 22,94 & 32,26 & $+9,32$ \\
\hline Finland & 23,98 & 32,37 & $+8,39$ \\
\hline France & 24,28 & 27,26 & $+2,98$ \\
\hline Germany & 26,82 & 27,14 & $+0,32$ \\
\hline Greece & 26,97 & 35,87 & $+8,90$ \\
\hline Ireland & 32,33 & 37,98 & $+5,65$ \\
\hline Italy & 25,85 & 31,76 & $+5,91$ \\
\hline Luxembourg & 24,68 & 28,47 & $+3,79$ \\
\hline Malta & 28,78 & 36,36 & $+7,58$ \\
\hline Netherlands & 19,66 & 22,37 & $+2,71$ \\
\hline Portugal & 29,22 & 37,53 & $+8,31$ \\
\hline Spain & 21,93 & 27,4 & $+5,47$ \\
\hline Sweden & 26,44 & 28,51 & $+2,07$ \\
\hline United Kingdom & 24,39 & 26,66 & $+2,27$ \\
\hline MEAN WE & 25,49 & 30,90 & $+5,41$ \\
\hline \multicolumn{4}{|c|}{ Central and Eastern Europe } \\
\hline Bulgaria & 25,53 & 44,18 & $+18,65$ \\
\hline Czech Republic & 27,01 & 31,60 & $+4,59$ \\
\hline Estonia & 27,11 & 24,95 & $-2,16$ \\
\hline Hungary & 28,87 & 35,12 & $+6,25$ \\
\hline Latvia & 42,28 & 29,30 & $-12,98$ \\
\hline Lithuania & 38,37 & 38,00 & $+0,37$ \\
\hline Poland & 38,42 & 34,62 & $-3,8$ \\
\hline Romania & 36,79 & 43,41 & $+6,62$ \\
\hline Slovakia & 34,56 & 40,09 & $+5,53$ \\
\hline Slovenia & 28,84 & 27,04 & $-1,8$ \\
\hline MEAN CEE & 32,78 & 34,83 & $+2,13$ \\
\hline MEAN EU27 & 28,19 & 32,38 & $+4,19$ \\
\hline
\end{tabular}

Note: Cell entries are mean values of users' representative deficit by national voting district (i.e., country of residence).

Although there are other international databases measuring the quality of the public sphere, the chosen databases are best suited for relating to our VAA data. Not only do World Press Freedom and Voice \& Accountability indices provide observations for all 27 countries profiled in by the selected VAAs, they are also annually constructed databases, thereby allowing us find matching years with our VAA data so that we may carry out longitudinal analysis. ${ }^{7}$ Note that higher values of the

\footnotetext{
${ }^{7}$ For both elections, we resort to the values of the indices relative to
}

World Press Freedom Index corresponds with less press freedom, whereas higher values of the Voice \& Accountability index corresponds with a comparatively more discursively open and accountable political system. Finally, turnout is measured through the percentage of eligible voters casting their ballot in the EP elections of 2009 and 2014 respectively. The analysis also includes countries' GDP per capita (as provided by the World Bank) as a statistical control for potential effects of the economic conditions across the financial crisis. Descriptive statistics for all variables included in the statistical analyses are presented in Table 2.

Before presenting the results of our analyses, it is worth commenting briefly on the modelling strategy employed. As discussed above, there are a wide variety of factors which are theoretically important when considering representative deficit. This suggests an analytical model which contains multiple independent variables. However the number of observations (27 countries observed in both 2009 and 2014) is very low for estimating such a model. Furthermore, the multiplicity of potential independent variables increases the chances of committing a Type I error simply through testing multiple potential combinations.

Given this situation, we have adopted a three pronged strategy. First, we estimate univariate OLS regressions for each variable of interest for both 2009 and 2014 waves, to establish if there is a statistically significant correlation between the variable in question and representative deficit. These single regressions are reasonable in terms of statistical power, and the opportunity to run the same test in both 2009 and 2014 enhances confidence in the results and makes Type I errors less likely. Second, we estimate a full model including all relevant variables, again for the 2009 and 2014 waves. These full models allow us to see which variables, if any, remain significant once all potential factors are taken into account. ${ }^{8}$ Finally, we estimate a first difference model, which looks at the extent to which changes in independent variables correlate with changes in dependent variables. Again, this provides a further check for the results, decreasing the possibility of Type I errors. Our simple univariate and combined multivariate models are presented in Tables 3 and 4 respectively.

A number of findings stand out from these tables. Univariate relationships between our independent vari-

the respective previous year (i.e., 2008 and 2013) in order to exclude potential intervening effects of the election itself on experts' assessment. ${ }^{8}$ Inclusion of all variables in a multivariate model is justified by the lack of significant collinearity: correlations between independent variables are all below 0.6, with the sole exception of Voice \& Accountability and Years of Democracy in both 2009 ( $r=.84)$ and 2014 (r=.78). 
Tab. 2. Descriptive statistics of variables included in the analysis.

\begin{tabular}{|c|c|c|c|c|c|}
\hline 2009 & Mean & St. Dev. & Min & $\operatorname{Max}$ & $\mathrm{N}$ \\
\hline \multicolumn{6}{|l|}{ Dependent Variable } \\
\hline Representative Deficit & 28.19 & 5.60 & 19.66 & 42.28 & 27 \\
\hline \multicolumn{6}{|l|}{ Institutions } \\
\hline Electoral Threshold (\%) & 2.29 & 2.35 & 0.00 & 5.00 & 27 \\
\hline Number of Parties & 8.96 & 2.78 & 4.00 & 16.00 & 27 \\
\hline Number of Seats in EP & 29.07 & 26.38 & 5.00 & 99.00 & 27 \\
\hline Decentralization (dummy) & 0.30 & 0.47 & 0.00 & 1.00 & 27 \\
\hline Years of Democratic Rule $(1945=0)$ & 42.59 & 21.02 & 16.00 & 64.00 & 27 \\
\hline \multicolumn{6}{|l|}{ Public Sphere } \\
\hline World Press Freedom Index (2008) & 5.09 & 2.80 & 1.50 & 12.50 & 27 \\
\hline Voice and Accountability (2008) & 1.15 & 0.30 & 0.51 & 1.60 & 27 \\
\hline Turnout in EP elections (\%) & 46.16 & 18.91 & 19.60 & 90.80 & 27 \\
\hline \multicolumn{6}{|l|}{ Controls } \\
\hline GDP per capita (in Euro) & 32603 & 20592 & 6738 & 100735 & 27 \\
\hline 2014 & Mean & St. Dev. & Min & Max & $\mathrm{N}$ \\
\hline \multicolumn{6}{|l|}{ Dependent Variable } \\
\hline Representative Deficit & 32.36 & 6.32 & 22.37 & 44.18 & 27 \\
\hline \multicolumn{6}{|l|}{ Institutions } \\
\hline Electoral Threshold (\%) & 2.10 & 2.32 & 0.00 & 5.00 & 27 \\
\hline Number of Parties & 8.70 & 2.57 & 3.00 & 13.00 & 27 \\
\hline Number of Seats in EP & 27.41 & 25.21 & 6.00 & 96.00 & 27 \\
\hline Decentralization (dummy) & 0.30 & 0.47 & 0.00 & 1.00 & 27 \\
\hline Years of Democratic Rule $(1945=0)$ & 47.59 & 21.02 & 21.00 & 69.00 & 27 \\
\hline \multicolumn{6}{|l|}{ Public Sphere } \\
\hline World Press Freedom Index (2013) & 16.59 & 7.33 & 6.38 & 28.58 & 27 \\
\hline Voice and Accountability (2013) & 1.10 & 0.38 & 0.29 & 1.68 & 27 \\
\hline Turnout in EP elections (\%) & 44.01 & 18.49 & 13.05 & 90.40 & 27 \\
\hline \multicolumn{6}{|l|}{ Controls } \\
\hline GDP per capita (in Euro) & 34754 & 22283 & 7713 & 110665 & 27 \\
\hline
\end{tabular}

ables and the representative deficit goes by and large in the expected direction. Countries with lower electoral thresholds and a comparatively higher number of relevant parties experience lower degrees of representative deficit (although the regression coefficients fall short of conventional levels of statistical significance in 2014). The number of years spent as a democracy also appears strongly related to lower representative deficit in 2009 and 2014, though the effect decreases in 2014 (this might be expected as the relative importance of the difference in years as a democracy should decrease as time goes by). Decentralisation is a significant predictor of lower degrees of representative deficit in both election years as well. No statistical association would seem to appear between representative deficit and the electoral size of the country.

Moving to variables more directly relating to the public sphere, we can see that voice and accountability has an especially impressive correlation with the representative deficit. In every case the relationship is highly significant (in spite of the extremely low number of observations) and signed as expected. Higher degrees of press freedom would also seem to correlate negatively with the extent of of representative deficit, though the relationship is statistically significant only in 2014. As expected turnout rates in EP elections correlate positively with lower degrees of the representative deficit, but the coefficient is statistically significant only in 2009 . 
Tab. 3. Univariate OLS regression estimates.

\begin{tabular}{lccc}
\hline 2009 & $\mathrm{~b}$ & $\mathrm{~S} . \mathrm{E}$. & $\mathrm{P}>|\mathrm{t}|$ \\
\hline Institutions & & & \\
Electoral Threshold & 1.33 & 0.39 & $\mathbf{0 . 0 0 2}$ \\
Number of Parties & -0.81 & 0.37 & $\mathbf{0 . 0 3 8}$ \\
Number of Seats in EP & -0.04 & 0.04 & 0.376 \\
Decentralization & -4.89 & 2.20 & $\mathbf{0 . 0 3 6}$ \\
Years of Democratic Rule & -0.16 & 0.04 & $\mathbf{0 . 0 0 1}$ \\
Public Sphere & & & \\
World Press Freedom Index & 0.06 & 0.40 & 0.887 \\
Voice and Accountability & -11.48 & 2.88 & $\mathbf{0 . 0 0 1}$ \\
Turnout in EP elections & -0.11 & 0.05 & $\mathbf{0 . 0 5 2}$ \\
Controls & & & \\
GDP per capita (in Euro $\left.{ }^{\star} 1000\right)$ & -0.15 & 0.05 & $\mathbf{0 . 0 0 2}$ \\
\hline 2014 & $\mathrm{b}$ & $\mathrm{S} . \mathrm{E}$. & $\mathrm{P}>|\mathrm{t}|$ \\
\hline Institutions & & & \\
Electoral Threshold & 0.64 & 0.53 & 0.236 \\
Number of Parties & -0.67 & 0.47 & 0.172 \\
Number of Seats in EP & -0.07 & 0.05 & 0.155 \\
Decentralization & -5.65 & 2.47 & $\mathbf{0 . 0 3 1}$ \\
Years of Democratic Rule & -0.13 & 0.05 & $\mathbf{0 . 0 2 8}$ \\
Public Sphere & & & \\
World Press Freedom Index & 0.30 & 0.16 & $\mathbf{0 . 0 8 0}$ \\
Voice and Accountability & -10.36 & 2.64 & $\mathbf{0 . 0 0 1}$ \\
Turnout in EP elections & -0.07 & 0.07 & 0.287 \\
Gontrols & & & \\
\hline GDP per capita (in Euro*1000) & -0.14 & 0.05 & $\mathbf{0 . 0 1 1}$ \\
\hline
\end{tabular}

Note: Dependent variable: Representative Deficit at country level.

Finally, our GDP per capita measure shows that there is a strong relationship with the dependent variable, with richer countries reporting systematically lower values of the representative deficit.

In terms of the full model, there are fewer statistically significant results. Loss of statistical significance is especially pronounced in the case of institutional-level variables. After controlling for all other variables, only the decentralization variable is significant in both years, while electoral threshold remains within conventional levels of statistical significance only in 2009 and years of democratic rule only in 2014.

Moving to public sphere variables, the multivariate analysis confirms the strong impact of the Voice \& Accountability index. Press freedom also emerges as statistically significant in both models, but counter to our expectations and preliminary results: once all other factors are taken into account, higher press freedom would
Tab. 4. Multivariate analysis, OLS estimates.

\begin{tabular}{|c|c|c|c|c|}
\hline 2009 & B & S.E. & $\mathrm{t}$ & $\mathrm{P}>|\mathrm{t}|$ \\
\hline \multicolumn{5}{|l|}{ Institutions } \\
\hline Electoral Threshold & 0.91 & 0.43 & 2.11 & 0.050 \\
\hline Number of Parties & 0.02 & 0.34 & 0.04 & 0.965 \\
\hline Number of Seats in EP & 0.01 & 0.04 & 0.28 & 0.780 \\
\hline Decentralization & -4.13 & 1.90 & -2.18 & 0.044 \\
\hline Years of Democratic Rule & 0.02 & 0.09 & 0.24 & 0.811 \\
\hline \multicolumn{5}{|l|}{ Public Sphere } \\
\hline World Press Freedom Index & -0.93 & 0.43 & -2.17 & 0.044 \\
\hline Voice and Accountability & -12.48 & 7.35 & -1.7 & 0.099 \\
\hline Turnout in EP elections & -0.01 & 0.06 & -0.18 & 0.856 \\
\hline \multicolumn{5}{|l|}{ Controls } \\
\hline $\begin{array}{l}\text { GDP per capita (in } \\
1.000^{\star} \text { Euro) }\end{array}$ & -0.01 & 0.07 & -0.16 & 0.878 \\
\hline Constant & 45.80 & 8.96 & 5.11 & 0.000 \\
\hline R-Squared & \multicolumn{4}{|c|}{0.74} \\
\hline 2014 & $\mathrm{~b}$ & S.E. & $\mathrm{t}$ & $\mathrm{P}>|\mathrm{t}|$ \\
\hline \multicolumn{5}{|l|}{ Institutions } \\
\hline Electoral Threshold & 0.35 & 0.46 & 0.76 & 0.457 \\
\hline Number of Parties & -0.43 & 0.42 & -1.04 & 0.314 \\
\hline Number of Seats in EP & -0.03 & 0.06 & -0.49 & 0.627 \\
\hline Decentralization & -4.56 & 2.45 & -1.86 & 0.080 \\
\hline Years of Democratic Rule & 0.24 & 0.10 & 2.32 & 0.033 \\
\hline \multicolumn{5}{|l|}{ Public Sphere } \\
\hline World Press Freedom Index & -0.48 & 0.28 & -1.71 & 0.097 \\
\hline Voice and Accountability & -21.35 & 6.21 & -3.44 & 0.003 \\
\hline Turnout in EP elections & 0.03 & 0.09 & 0.36 & 0.722 \\
\hline \multicolumn{5}{|l|}{ Controls } \\
\hline $\begin{array}{l}\text { GDP per capita (in } \\
1.000^{*} \text { Euro) }\end{array}$ & -0.09 & 0.09 & -0.99 & 0.335 \\
\hline Constant & 60.81 & 8.99 & 6.77 & 0.000 \\
\hline R-Squared & \multicolumn{4}{|c|}{0.65} \\
\hline
\end{tabular}

Note: Dependent variable: Representative Deficit at country level.

seem to result in comparatively higher degrees of representative deficit. Finally, the effect of electoral turnout seems to vanish along with that of GDP per capita. We would hence conclude that our data offers stronger support for the influence of the public sphere on the quality of representation, when compared to those variables related to the arrangement of the regime.

To test the robustness of these results and to dig deeper into causality, we estimated one First Difference (FD) model aimed at explaining across-time changes of 
Tab. 5. First-Difference Estimation (2014 - 2009).

\begin{tabular}{lccc}
\hline & $\mathrm{b}$ & $\mathrm{S} . \mathrm{E}$. & $\mathrm{P}>|\mathrm{t}|$ \\
\hline Institutions & & & \\
Electoral Threshold & 0.43 & 0.95 & 0.652 \\
Number of Parties & 0.45 & 0.39 & 0.257 \\
Number of Seats in EP & 0.47 & 0.65 & 0.481 \\
Public Sphere & & & \\
World Press Freedom Index & -0.51 & 0.22 & $\mathbf{0 . 0 3 1}$ \\
Voice and Accountability & -42.20 & 13.35 & $\mathbf{0 . 0 0 5}$ \\
Turnout in EP elections & 0.14 & 0.12 & 0.271 \\
Controls & & & \\
GDP per capita (in & & & \\
1.000*Euro) & -0.08 & 0.33 & 0.811 \\
Constant & & & \\
R-Squared & 9.63 & 2.70 & $\mathbf{0 . 0 0 2}$ \\
\hline
\end{tabular}

Note: Dependent variable: Difference (2014-2009) in Representative Deficit at country level.

mean representative deficit at the country level. The FD estimator is intended to wipe out time invariant omitted variables using the repeated observations over time. In other words, estimation takes place by regressing "changes on changes" using OLS (Wooldridge, 2001). To put it more simply, changes in aggregate-level representative deficit across the five years under analysis (i.e., say representative deficit in Italy equals '25.9' in 2009 and ' 31.8 ' in 2014 , the value of the dependent variable for Italy equals to '5.9') are explained as a function of across-wave changes $(\Delta)$ in the key independent variables included in the previous models. Note that the variables related to decentralization and the number of years under democratic rule are excluded from this analysis as no change could be witnessed across the two time points under analysis.

The results, as presented in Table 5, point in the same direction of the previous analyses, and further provide support for the idea that decreasing representative deficit in a given country is linked to higher voice and accountability. The result also seems to suggest that it is linked to comparatively lower press freedom. However, it is worth noting that the degree of press freedom in a given country is included in the voice and accountability index, which is an aggregate index of a wide variety of measures. Hence, in this model, press freedom acts as a kind of "correction" to the more general Voice \& Accountability index, indicating that while increases in voice and accountability are generally positively correlated with decreases in representative deficit, increas- es that relate specifically to press freedom have less of an impact. This is supported by the univariate models, which showed no statistically significant correlation between press freedom and representative deficit.

\section{CONCLUSION}

This paper began with the contention that the degree of ideational congruence between citizens and their representatives constitutes the central normative problem of democracy. While this statement may be relatively uncontroversial, empirical studies have rarely given centre stage to the representative deficit. Perhaps this is in part due to the fact that databases documenting the quality of democracy across countries tend not to provide objective measures of this phenomenon. With the availability of international VAAs, such as those employed in this paper, we are in a position to provide relatively reliable measures of the representative deficit across countries and across time. This, in turn, puts us in a unique position to contribute towards an understanding of those factors that tend to impact the quality of ideational representation in the EU.

Our descriptive statistics are interesting in themselves, corroborating widespread reports of a democratic decline in the Western world, as well as a notable gap in the quality of representation between Western and Eastern Europe. Interestingly, it was observed that those countries suffering from a loss of financial sovereignty in Europe had an above average worsening of their representative deficit between 2009 and 2014. While we could not offer systematic evidence for the relationship between financial sovereignty and the representative deficit, it stands to reason that ideational congruence will suffer when the communicative conveyer belt between citizens and representatives is shut down on salient domains typically reserved for domestic government due to the intervention of international and supranational bodies.

When it comes to determining those variables that most impact the representative deficit, we found contrary to expectations that many of the institutional variables we explored do not have a substantial impact on the dependent variable. What did stand out as influential are factors more directly related to the public sphere, namely voice and accountability and press freedom. However, while the former clearly emerged as the most important variable influencing the representative deficit, press freedom was found to be negatively correlated with the representative deficit. As said, there are methodological grounds to believe in the spuriousness of this correla- 
tion. Nevertheless, our analyses would not seem to offer support for the hypothesis that increasing press freedom increases the quality of representation.

A potential explanation for this unexpected relationship between press freedom and representation can be found in the work of Bernard Manin (1997). On Manin's view, press freedom is essential for a good democracy, yet the proliferation of media inevitably leads to a much wider diversity of opinions than in a relatively unfree press environment. On this view it stands to reason that greater diversity of opinions, made possible by a free press, will make it more difficult for representatives to find ideational congruence with their citizens in political space. The general lesson here is that, while representation may be at the heart of democracy, everything that is democratic will not necessarily improve ideational congruence.

To conclude, there are both unsurprising and surprising findings in this paper. Somewhat unsurprisingly, we have found a decline in the representative deficit across Europe; a persistent difference between Western and Eastern Europe; and the importance of voice and accountability in determining the representative deficit. More unexpected were our findings concerning the relative unimportance of institutional factors, electoral turnout and GDP for our dependent variable, as well as the relationship between press freedom and the representative deficit. While we do not claim that ideational congruence between representatives and the represented is the only relevant factor for assessing a good democracy, or even for evaluating good representation, what we do insist upon is the importance of such a measure to any research on the quality of democracy. This paper has been an attempt to advance research on this fundamental question within the European context in a crossnational and longitudinal analysis.

\section{REFERENCES LIST}

Alvarez, R. M., Levin, I., Mair, P. \& Trechsel, A. (2014). Party preferences in the digital age: The impact of voting advice applications. Party Politics 20(2), 227-236.

Becker, L. B., Vlad, T., \& Nusser, N. (2007). An evaluation of press freedom indicators. International Communication Gazette, 69(1), 5-28.

Benoit, K., \& Laver, M. (2012). The dimensionality of political space: Epistemological and methodological considerations. European Union Politics, 13(2), 194218.

Bohman, J. (2010). Democratising the global order: from communicative freedom to communicative power. Review of International Studies, 36(2), 431-47.
Bolleyer, N., \& Reh, C. (2012). EU legitimacy revisited: the normative foundations of a multilevel polity. Journal of European Public Policy, 19(4), 472-490.

Bright, J., Garzia, D., Lacey, J., \& Trechsel, A. (2016). Europe's voting space and the problem of secondorder elections: A transnational proposal. European Union Politics, 17(1), 184-198.

Chambers, S. (2012). "Deliberation and mass democracy", in Deliberative systems: Deliberative democracy at the large scale, edited by John Parkinson and Jane Mansbridge. Cambridge: Cambridge University Press.

Dahl, R. A. (1989). Democracy and its critics. New Haven: Yale University Press.

Dalton, R. J. (2015) Party representation across multiple issue dimensions. Party Politics, online first.

Dalton, R. J., Farrell, D., \& McAllister, I. (2011) Political Parties and Democratic Linkage. Oxford: Oxford University Press.

Downs, A. (1957). An economic theory of political action in a democracy. Journal of Political Economy, 65(2), 135-150.

Garzia, D., \& Marschall, S. (2016). Research on Voting Advice Applications: State of the art and future directions. Policy \& Internet 8(4), 376-390.

Garzia, D. \& Marschall, S. (2019). "Voting Advice Applications" in Oxford Research Encyclopedia, edited by William R. Thompson. Oxford: Oxford University Press.

Garzia, D., Trechsel, A. \& De Sio, L. (2017). Party placement in supranational elections. An introduction to the euandi2014 dataset. Party Politics, 23(4), 333-341.

Gerring, J., \& Thacker, S. C. (2008). A Centripetal Theory of Democratic Governance. Cambridge: Cambridge University Press.

Habermas, J. (1996). Between Facts and Norms: Contributions to a Discourse Theory of Law and Democracy. Oxford: Polity Press.

Hooghe, M. (2003). Value congruence and convergence within voluntary associations: ethnocentrism in Belgian organizations. Political Behavior, 25(2), 151-175.

Kaufmann, D., Kraay, A., \& Mastruzzi, M. (2009). Governance matters VIII: aggregate and individual governance indicators, 1996-2008. World Bank Policy Research Working Paper N. 4978.

Manin, B. (1997). The Principles of Representative Government, Cambridge: Cambridge University Press.

Marschall, S. (2014). "Profiling users", in Matching Voters with Parties and Candidates: Voting Advice Applications in a Comparative Perspective, edited by Diego Garzia \& Stefan Marschall. Colchester: ECPR Press.

Montesquieu (1989) [1750]. Spirit of the Laws, edited by A. M. Cohler, B.C. Miller and H. S. Stone. Cambridge: Cambridge University Press. 
Mouffe, C. (1999). Deliberative Democracy or Agonistic Pluralism. Social Research, 66(3), 745-58.

Rehfeld, A. (2009). Representation rethought: on trustees, delegates, and gyroscopes in the study of political representation and democracy. American Political Science Review, 103(2), 214-230.

Rohrschneider, R., \& Whitefield, S. (2012). The Strain of Representation. Oxford: Oxford University Press.

Rose-Ackerman, S. (2007). From elections to democracy in Central Europe: Public participation and the role of civil society. East European Politics and Societies, 21(1), 31-47.

Sissenich, B. (2010). Weak states, weak societies: Europe's east-west gap. Acta Politica, 45(1/2), 11-40.

Thomassen, J., \& Schmitt, H. (1999). "Policy congruence", in Political Representation and Legitimacy in the European Union, edited by Hermann Schmitt \& Jacques Thomassen. Oxford: Oxford University Press.

Trechsel, A. H., \& Mair, P. (2011). When parties (also) position themselves: An introduction to the EU Profiler. Journal of Information Technology \& Politics, 8(1), 1-20.

Wooldridge, J. M. (2001). Applications of generalized method of moments estimation. Journal of Economic Perspectives, 15(4), 87-100. 